\title{
Mucormycosis of the Middle Ear: A Case Report with Review of Literature
}

\author{
P. Hazarika · Joyse Zachariah $\cdot$ John Victor • \\ Molly John · Chitra Devi · Prakash Abraham
}

Received: 25 September 2009/ Accepted: 11 December 2009/Published online: 23 February 2011

(C) Association of Otolaryngologists of India 2011

\begin{abstract}
Mucor is a saprophytic organism and commonly invades the nose and paranasal sinuses of immunocompromised and diabetic patients involvement of the middle ear and mastoid in a nondiabetic patients is very rare and this may be the first case report clinical presentation of ear pain with reference to the mastoid and upper neck may be the early symptoms unlike the foul smelling ear discharge as seen in atticoantral disease. Radical debridement in the form of M.R.M with or without the use of amphotericin B may suffice in non-diabetic patients this case is reported to highlight the point that mucormycosis can also involve middle ear and mastoid in nondiabetic patients.
\end{abstract}

Keywords Mucomycosis - MRM - CT scan - Nondiabetic · Attic perforation

\section{Introduction}

Mucormycosis and Aspergillus infections are seen more commonly in the nose and paranasal sinuses. Whereas candida and aspergillus fungus are the most common pathogen in the external auditory canal. The invasive variety of both mucormycosis and aspergillosis are seen mostly in diabetic patients [1]. Mucormycosis of the middle ear is a very rare clinical entity. Since 2007-2009 we

P. Hazarika $(\bowtie) \cdot$ J. Zachariah $\cdot$ J. Victor $\cdot$ M. John $\cdot$ C. Devi . P. Abraham

New Medical Centre, Abu Dhabi, UAE

e-mail: produl_ent@rediffmail.com have treated one such case of mucormycosis of the middle ear in a non-diabetic patient in New Medical Center, Abu Dhabi.

\section{Case Report}

Mr. P.S, a 24-year-old male from Nepal was first seen on 05/04/09 in the ENT clinic of NMC for his complaint of Left ear pain of 6 months duration. The pain was dull aching and confined to the post auricular region with referral to the left upper neck. He also gave the history of occasional minimal mucoidal non foul smelling discharge 7 years prior to this visit which he revealed only after repeated questioning. His Left ear hearing was reduced when compared to the right side. On clinical examination, external auditory canal was dry, tympanic membrane (pars tensa) appeared dull and had an attic perforation. Minimal dark and dry debris were seen through the dry perforation (Fig. 1). X-ray mastoids showed left sclerosed mastoid. Audiogram revealed left moderate conductive hearing loss. CT scan temporal bone done on 23/05/09 reported as soft tissue attenuation in the left middle ear cavity and mastoid antrum with bony widening and thinning of tegmen tympani. Imaging findings are suggestive of cholesteatoma formation (Fig. 2a, b). There was soft tissue opacity seen in both ethmoidal and left sphenoidal sinus and termed as incidental findings (Fig. 3). Haematological investigation was within normal limit. The case was clinically diagnosed as atticoantral otitis media and therefore a modified radical mastoidectomy was done on 20/06/09. Inside out mastoidectomy was done after elevating and preserving the canal skin. On exploration, attic and antrum were filled with greenish soft tissue debris (Fig. 4a). After complete clearance of the middle ear and mastoid, the meatal wall 


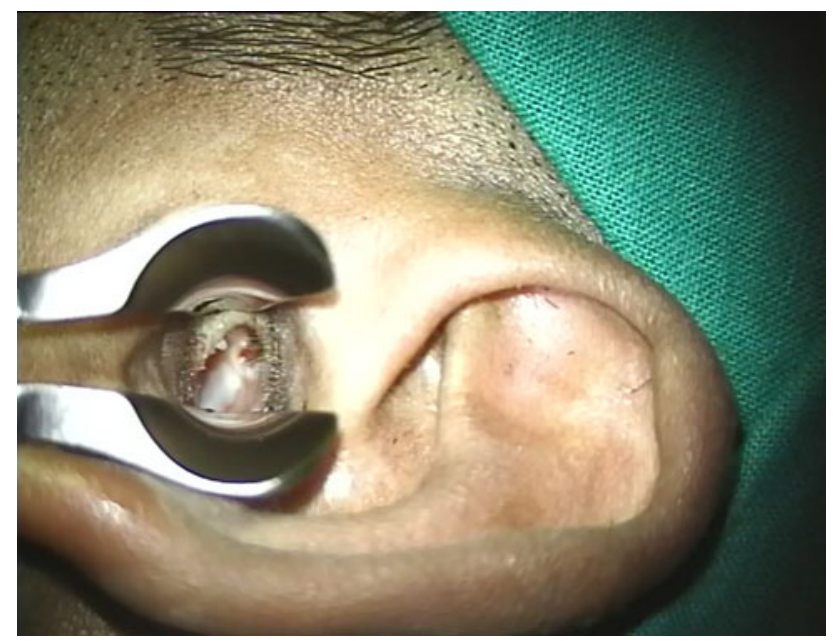

Fig. 1 Left tympanic membrane showing attic perforation
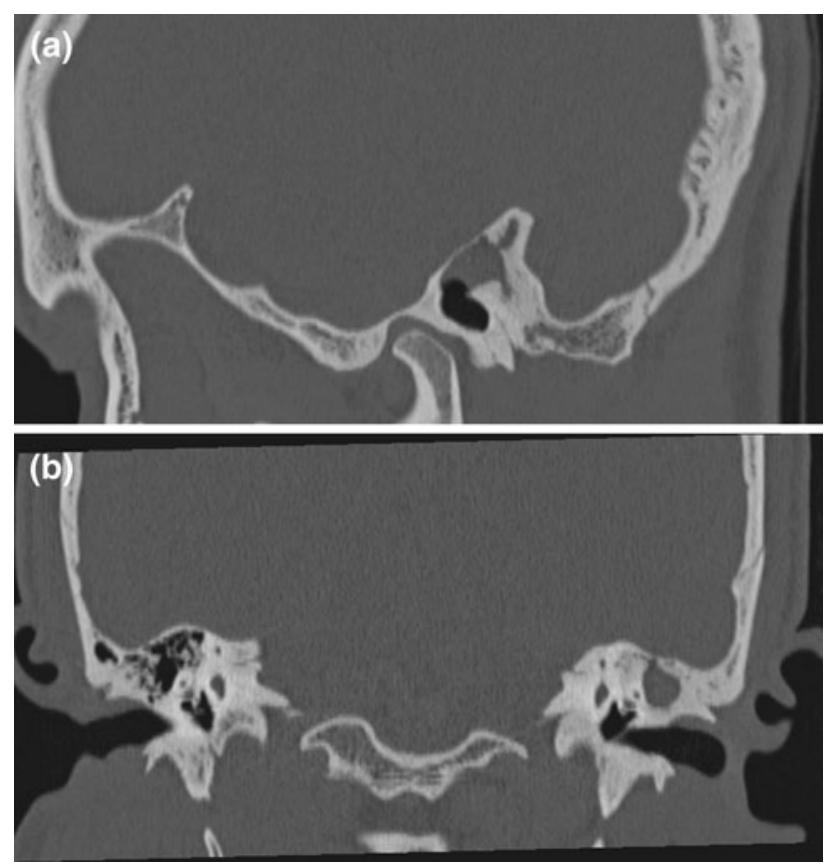

Fig. 2 CT scan showing soft tissue attenuation in the left middle ear cavity and mastoid antrum with bony widening and thinning ot tegman tympani

was put back to the mastoid bowl (Fig. 4b). Wound closed after conchomeatoplasty. Histopathology of the greenish soft tissue debris showed tangled masses of fungus, thin walled, nonseptate, broad, with irregular parallel contour haphazardly branching at right angles with bulbous tips and diagnosed as mucormycosis (Fig. 5a-c). Fungal culture could not be done, because tissue was sent in formaldehyde solution. This is because fungal infection was not suspected

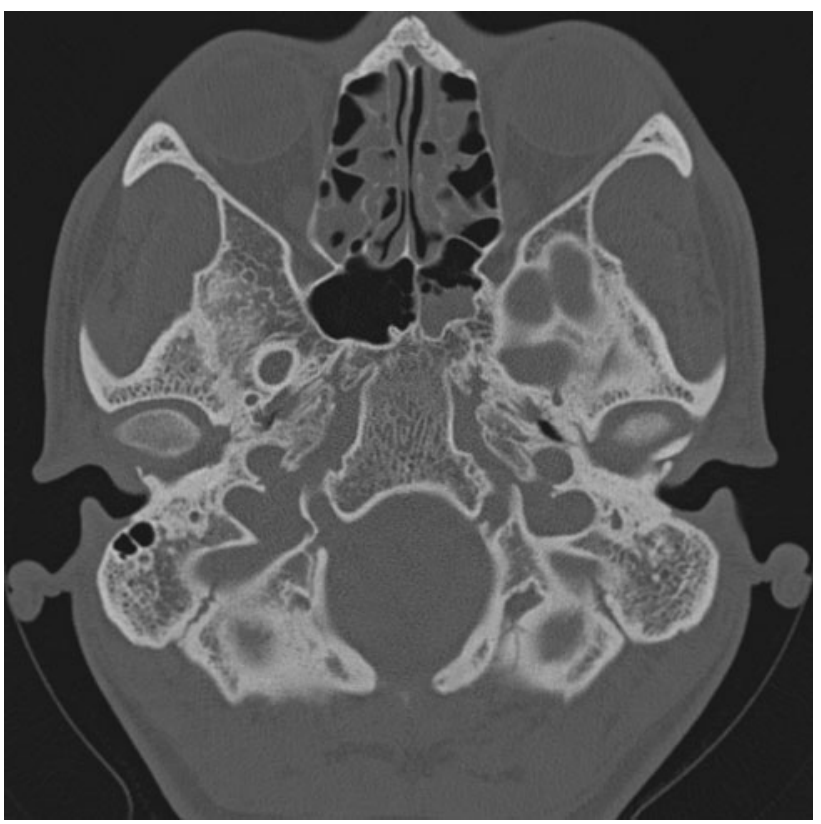

Fig. 3 CT scan showing opacity in both ethmoids and left sphenoid

in our initial diagnosis. Amphotericin B was not started immediately but decided to start at the first evidence of recurrence. Last followup done on 14/09/09 showed a well epithelialised mastoid bowl with no recurrence of fungus. Meatoplasty opening is adequate (Fig. 6).

\section{Discussion}

Incidence of fungal infection in middle ear and mastoid is very rare. Review of literature shows very few cases of temporal bone mucormycosis that have been reported [2-5] in diabetics and immunosuppressed people. Most of these cases were treated with amphotericin B and radical excision of the infected tissues but two of the four reported cases succumbed to their disease. Olalla et al. [4] reported a case of middle ear mucor mycosis in a patient previously treated for acute myeloid leukemia. Yun et al. [5] first reported a case of middle ear mucor mycosis with facial palsy in a diabetic patient. Mucormycosis of the middle ear and mastoid in nondiabetic patients has not been reported in the English literature in this part of the world to the best of our knowledge. This infection is caused by the family of mucoraceae which belongs to the class of phycomycetes [6]. Hence both the terms mucormycosis and phycomycosis are justifiable [7,8].

The diagnosis is recognized but not specifically identified according to the species in tissues by large broad nonseptae, hyaline, branching hyphae. These resemble cellophane tubes and are 7-10 microns in 

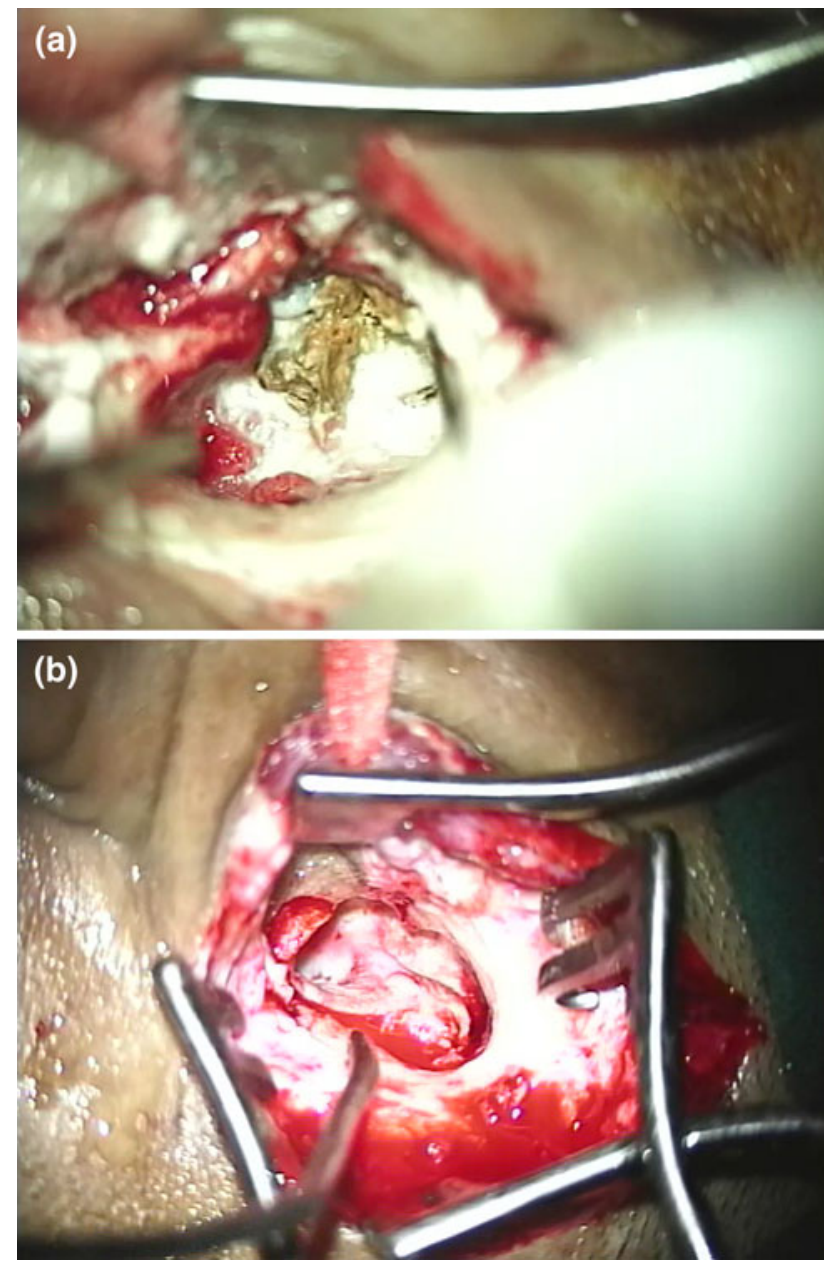

Fig. 4 Intraoperative photograph showing greenish debris in attic and antrum, canal skin in mastoid bowl

width and 100-200 microns in length. These organisms are often easily identified in the routine $\mathrm{H} \& \mathrm{E}$ stained sections because of their very large size (up to $30 \mathrm{mn}$ in diameter) but may be better visualized in PAS or silver metheramine stained section. Spores of this fungus are only very rarely seen. The organism proliferates in the tissue vessel wall and perineural spaces, however they have a predilection for the muscle layer of arteries as well as veins and lymphatics. This causes vessel thrombosis and tissue infarction. Mucormycosis is almost always invasive and spreads to the cranial cavity and orbit with specific predilection for vessel walls [9-12]. When it occurs in immunosuppressed patients it is always fatal. Mucormycosis of the middle ear in non-diabetic patients appears to be non-invasive and is not fatal. The noninvasive variety may occur as indolent infection producing symptoms similar to CSOM as seen in our case.
Mucormycosis can infect the nose and the paranasal sinuses through organisms contained in the inhaled dust and is commonly seen in farmers. Portal of entry to the middle ear and mastoid in otherwise healthy individual is difficult to explain. Probable portal of entry to the middle ear is either from nasopharynx through Eustachian tube to antrum or mesotympanum or through the perforated tympanic membrane. The fungus might have entered through the preexisting perforation in the tympanic membrane. Eustachian tube route in this patient may also be likely because there was radiological evidence of opacity of ethmoid and left sphenoid sinus. However there is no clinical sign and symptom. Why and how this fungus has entered the middle ear of this case is debatable and needs further explanation. Our patient first presented with pain in the ear with referral to the upper neck. He complained of ear discharge only for a while 7 years back. Clinical evidence with attic perforation is more in favour of otitis media. CT scan findings of mucormycosis in a nondiabetic temporal bone has not been specific and may show bone destruction, sclerosis, evidence of soft tissue mass similar to cholesteatoma as seen in our case.

The rarity of this condition makes it difficult for the clinician to suspect middle ear mucormycosis as a principal diagnosis. Clinical presentation of this condition in nondiabetic patient will be similar to atticoantral disease but probably with the chief complaint of predominant ear pain with referral to the mastoid and neck.

Management of invasive form of mucormycosis will require the use of IV Amphotericin B, radical debridement of the affected tissue, as well as control of the predisposing factors such as diabetes. The treatment has been supplemented with granulocyte transfusion and bone marrow transplantation in select cases [13]. Prince and Stevenson [14] have explained the role of hyperbaric oxygen therapy on presumption that increased the oxygenation of the affected tissues distal to the occluded vessel and decrease local acidosis and enhance the activity of the fungicidal medication Olala I and Ortin M also reported stem cell bone marrow transplantation successfully in a 52-year-old male who developed invasive middle ear mucor mycosis.

Whereas noninvasive variety does not need such aggressive treatment. Radical debridement of the fungal debris with wide conchomeatoplasty for adequate ventilation and drainage may suffice as seen in our case studied. However the patient should be on constant and regular followup to watch for recurrence.

\section{Summary}

Mucor is a saprophytic organism and commonly invades the nose and paranasal sinuses of immunocompromised and 

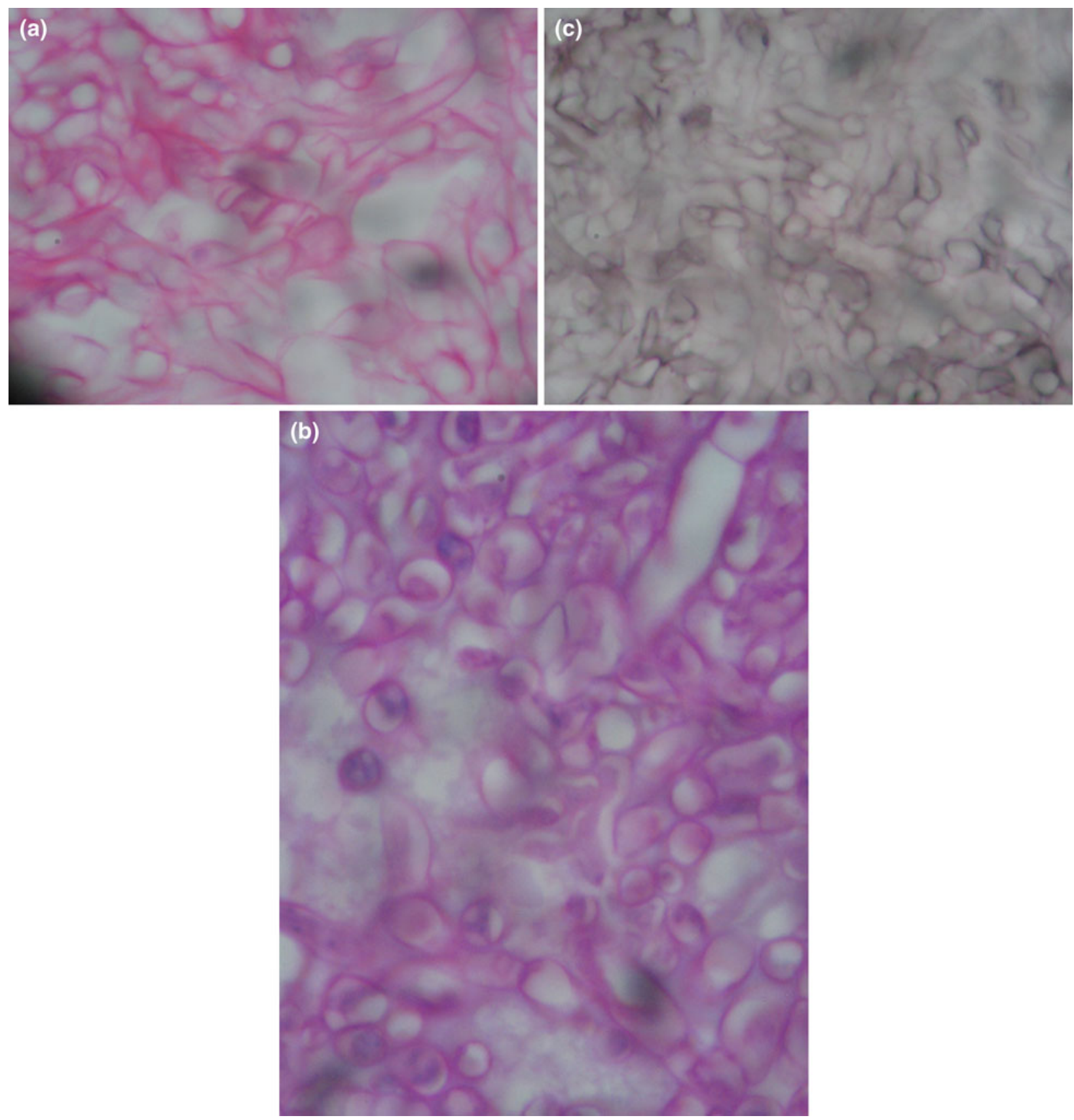

Fig. 5 Histopathology photomicrograph in haematocylin and eosin, dark magenta-PAS and dark methanamine silver stain, special stain for fungus showing tangled masses of fungus, thin walled, nonseptate,

diabetic patients. Involvement of the middle ear and mastoid in a nondiabetic patient is very rare and this maybe the first case report. Clinical presentation of ear pain with reference to the mastoid and upper neck may be early symptoms unlike the foul smelling ear discharge as seen in the attico antral broad with irregular parallel contur haphazardly branching at right angle with bulbous tip resembling cellophane tube

disease. Radical debridement in the form of modified radical mastoidectomy with or without the use of Amphotericin B may suffice in non-diabetic patients. This case is reported to highlight the point that mucormycosis can also involve middle ear and mastoid in non-diabetic patients. 


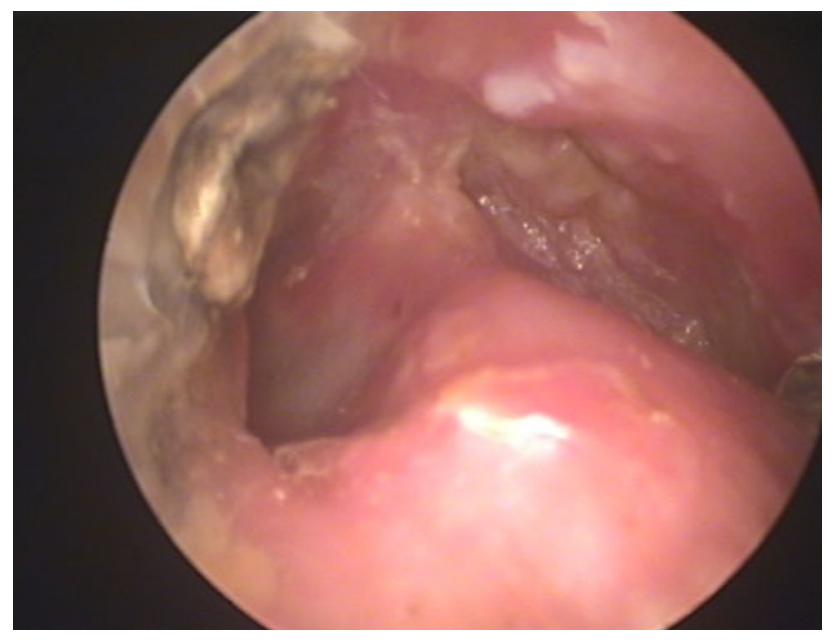

Fig. 6 Follow-up endoscopic photograph of postmastoidectomy cavity showing well epithelised mastoid cavity with intact tympanic membrane

Acknowledgments We are thankful to our Medical director Dr. C. R. Shetty of New Medical Center for allowing us to publish this interesting case report. We are also thankful to Mrs Madhurima Hazarika for the audiological tests done for this patient.

\section{References}

1. Hazarika P, Ravikumar V, Nayak RG, Roa PS, Shivnanda PG (1984) Rhinocerebral mucormycosis. Ear Nose Throat J 63: 100-106
2. Gussen R, Canalis RF (1982) Mucormycosis of the temporal bone. Ann Otol Rhinol laryngol 91:27-32

3. Macdonell RA, Donan GA, Kalnins RM, Richards MJ, Blandin PF (1987) Otocerebral mucormycosis-a case report. Clin Exp Neurol 23:225-232

4. Olalla I, Ortin M, Hermida G, Cortes MA, Richard C, Iriondo A, Mozota ML, Zubizarreta A (1996) Autologus peripheral blood stem cell transplantation in a patient with previous invasive middle ear mucormycosis. Bone Marrow Transpl 18(6):1183-1184

5. Yun MW, Lui CC, Wj Chen (1994) Facial paralysis secondary to tympanic mucormycosis: case report. Am J Otolaryngol 15(3): 413-414

6. Bergstrom L, Hemenway WG, Barnhant RA et al (1970) Rhinocerebral and otologic mucormycosis. Ann Otol Rhinol Laryngol 79:70-81

7. Gass JDM (1961) Occular manifestation of acute mucormycosis. Arch Ophthalmol 65:226-237

8. Joe LK, Eng NI, Tyokronegord J et al (1959) Phycomycosis of central nervous system associated with diabetes mellitus in Indonesia. Am J Clin Pathol 32:62-70

9. Reeves DL, Dickson DR, Benjamin EL (1965) Phycomycosis of central nervous system. J Neurosurg 23:82-84

10. Sekhar LN, Duzvuy M, Rao GR (1980) Carotidcavernous sinus thrombosis caused by Aspergollo Fumigatous. J Neurosurg 52: $120-125$

11. Cowrey WR, New PFJ, Price DL (1972) Angiographic manifestation of craniofacial phycomycosis. Radiology 103:329-334

12. Mc Cormick WF, Schochet SS Jr, Weaver PA (1975) Disseminated aspergillosis, aspergillous end ophthalmitis optic nerve infraction and carotid artery thrombosis. Arch Pathol 99:353-359

13. Macgill JJ, Simpson G, Healy GB (1980) Falminant aspergellosis of the nose and paranasal sinuses-a new clinical entity. Laryngoscope 90:748S-754S

14. Price JC, Stevans DL (1980) Hyperbaric oxygen in the treatment of rhinocerebral mucormycosis. Laryngoscope 90:737-747 